edition. The series has been designed to present in simple and, so far as possible, non-technical terms the essentials of each branch of the subject, so that it might be of practical service to all who are interested in the motor-car. With this aim in view, its principal features have been descriptions and explanations of the construction and operation of the several parts of the car. Theory has only been introduced to a limited extent, and in the present volume a short introduction puts the reader in possession of the main points as to the theory of carburation, the chemical and thermal properties of fuels, and the process of combustion. Starting from the simplest types of carburettor, the author builds up a picture of the development of this delicate piece of apparatus as further and further improvements were indicated by the need of greater economy and smoother running of the engine. He retains descriptions of older models because they embody important and interesting principles.

Of up-to-date types a large number are illustrated and described, and among the more recent developments dealt with are the various types of British and foreign carburettors having original systems of mixture compensation, automatic air chokes, acceleration pumps, power jets and other special features. The subject is treated very broadly, as, in addition to those for motor-cars and motor-cycles, carburettors for aircraft are also included, so that with the chapters treating of such ancillary matters as air cleaners, fuel feed systems, design of inlet manifolds, vaporization and testing, tuning and trouble tracing, the information given is very complete of its kind. In its extended form it should continue to prove of great help to motorists, repairers and students and to enjoy a full measure of popularity.

\section{Theory of Alternating-Current Machinery}

By Alexander S. Langsdorf. (Electrical Engineering Texts.) Pp. xviii +788 . (New York and London: McGraw-Hill Book Co., Ine., 1937.) $36 s$.

7 HIS large volume is devoted solely to the theory 1 of the steady state of electromagnetic A.c. machinery (thus excluding electronie devices such as mercury arc rectifiers). Questions of design are touched only so far as they form the background from which the theoretical problems arise. The wide field thus available enables the author to adopt a comprehensive and at the same time broad and easily readable treatment. A specially commendable feature of the book is that the usual analysis by means of vector diagram and complex algebra is always preceded by a very full discussion of the physical relations. In this connexion the chapter on asynchronous machines, which can well be read independently of the rest of the book, should be of special interest to students.

Other noteworthy features of the book are: in the introductory part a special chapter on the theory of polyphase current systems which includes an introduction to the method of symmetrical components, in the treatment of the transformer a discussion of the transformer with three windings, and in the chapter on synchronous machines a simplified presentation of the Doherty-Nickle theory for the calculation of armature reaction in machines with salient poles. The book can be thoroughly recommended.

A. B.

\section{Autographic Indicators for Internal Combustion Engines}

By J. Okill. Pp. 88. (London : Edward Arnold and Co., 1938.) 5s. net.

7 HIS is a subject which has been somewhat neglected and, as a result, connected information regarding the use of indicators on internal combustion engines is not readily obtainable. The author, who designed that most useful instrument, the Okill maximum pressure indicator, has given the matter much study and, in this monograph, presents a range of information and suggestions which should be most acceptable to those who have not had an extensive experience in the manipulation of these instruments. His survey is limited to the combined piston, spring and pencil-lever types, and traces their development from the original instrument devised by Watt about 1790 to the very carefully proportioned and accurate types now made to suit the severe requirements imposed on them by high-speed internal combustion engines. The possibility of inaccuracy and distortion of diagrams arising from piston friction, overheating and mishandling are pointed out and the methods of testing and calibrating the pencil movements are described. Then after dealing with inertia effects, spring vibrations and the correct forms of connectors, operating gears and other details, a number of present-day instruments are described and explained. The book should therefore be a most useful guide to the many engineers who depend on the indicator for periodical information as to how their engines are operating.

\section{Automatic Telephony}

By Charles W. Wilman. Second edition, thoroughly revised and reset. Pp. viii +208 . (London: The Technical Press, Ltd., 1938.) 10s. 6d. net.

A UTOMATIC or machine switched tele phony is A a very specialized subject; but the fundamental principles can be easily grasped. Few relevant text-books indicate these principles without confusing the student with circuit complexities; the author does provide a readable introduction both for students who intend to go further in their studies of the subject and for those who have to include an outline in their general study of electrical communication. The extensive study of the subject is not to be recommended to anyone who has not a suitable flair for the peculiar but necessary diagrammatic nomenclature.

One is surprised that the author does not give a technique for studying complicated switching problems; some form of pictorial shorthand is always used by engineers when studying machine switching circuits or devising new ones. There is likewise no complete circuit, such as a complete call through the minimum of a line-switch and selectors, or a director, 